\title{
"BARBARIC" CULTURAL PRACTICES: CULTURALIZING VIOLENCE AND THE FAILURE TO PROTECT WOMEN IN CANADA
}

\author{
Deepa Mattoo and Sydele E. Merrigan
}

\begin{abstract}
The introduction of Bill S-7, the Zero Tolerance for Barbaric Cultural Practices Act, in 2015 garnered major critical attention across Canada. Amid an already tense climate of anti-immigrant sentiment in the post-9/11 era, the title chosen for the bill by the Conservative-led government catalyzed xenophobia, perpetuated the "us versus them" rhetoric, and culturalized violence. While originally touted as an opportunity to enhance protection for girls and women against the "foreign" horrors of polygamy, early and forced marriage, and "honour"-based killings, Bill S-7 instead fanned the flames of xenophobia on a mass level, failed to protect women, and, in fact, created higher risk of harms for women who are victims of gender- or family-based violence. In this commentary, we provide an overview of Bill S-7, the amendments to legislation made as a result of its passing, and some of its many problematic elements. We address the barriers to disclosing violence in racialized communities and subsequently provide suggestions on how to effectively address gender- and family-based violence in Canada in an effort to support survivors and prevent further harm.
\end{abstract}

Keywords: forced marriages, immigrant families, precarious status, cultural racism

Deepa Mattoo MBA, LL.B is the Executive Director of Barbra Schlifer Commemorative Clinic, Toronto, and Adjunct Professor at Osgoode Hall Law School, 4700 Keele St, North York, ON M3J 1P3. Email: dmattoo@schliferclinic.com

Sydele E. Merrigan MPH is a Research Associate in the Faculty of Human and Social Development, HSD Building, Room A102, University of Victoria, 3800 Finnerty Road, Victoria BC V8P 5C2. Email: sydelemerrigan@uvic.ca

Note: Correspondence concerning this article should be addressed to Mandeep Kaur Mucina, School of Child and Youth Care, Human and Social Development, University of Victoria, 3800 Finnerty Road, Victoria, BC V8P 5C2. Email: mmucina@uvic.ca 
International Journal of Child, Youth and Family Studies (2021) 12(1): 124-142

In 2014, the federal Government of Canada introduced Bill S-7, the Zero Tolerance for Barbaric Cultural Practices Act (henceforth, Bill S-7), which criminalized participating in and supporting "barbaric cultural practices" such as early, forced, or polygamous marriage and "honour"-based violence ${ }^{1}$ (Zero Tolerance for Barbaric Cultural Practices Act, 2015). The Conservative-led government made several statements in support of the legal changes enacted under Bill S-7. For example, Joan Crockatt, Conservative member for Calgary Central, felt the bill provided "strong action to protect women and girls" in Canada and would keep immigrant women and girls from being "hampered ... by discriminatory cultural practices and barbaric cultural practices"2 and to protect victims of crime (Crockatt, 2015). Despite the broad protection it sought to afford, public discourse focused narrowly on the specific experiences in racialized $^{3}$ communities. While the stated purpose of the bill sounded noble, the criminalization of these practices had the potential to become a tool to further target and over-police racialized communities, perpetuate negative racial stereotypes, and push survivors and those experiencing violence further underground (Shalabi et al., 2015). In the context of Bill S-7, women who need protection from familial or gender-based violence, or are survivors of it, may be discouraged from coming forward to disclose their experiences as it may increase the risk of punitive measures, such as criminal sanctions or deportation, for their own family or community members. Ultimately, Bill S-7 further endangered the very people it claimed to protect.

The Conservative administration that tabled Bill S-7 claimed that in addition to protecting women and girls from violence, the bill would ensure that the Canadian government was at the forefront of efforts to respond to those suffering from violence, and to meet the needs of those most vulnerable to it. Critical to the discussion of responding to and protecting women from familial and gender-based violence, but almost entirely absent from house debates and public discourse, were preventing violence and learning from survivor input. The work of many feminist organizations and relevant literature on these issues demonstrates that the most effective preventive tools involve a multisectoral approach coupled with an intersectional education strategy (Mattoo \& Sekhar, 2012). Further, the knowledge and expertise of racialized survivors need to be at the forefront of these measures and included in debates about how to address violence against racialized women (Johnson \& Kapoor, 2013; Shalabi et al., 2015). Unless this is undertaken, state attempts to address violence against racialized women deteriorate into colonialist postures (e.g.,

\footnotetext{
${ }^{1}$ See Olwan (2013) for more information on "honour-based" violence and "honour" crime.

${ }^{2}$ The "barbaric cultural practices" referenced in Bill S-7 are situated on a larger continuum of gender-based and family violence. For more information, see Mucina (2018), Shalhoub-Kevorkian (2002), and Welchman and Hossain (2005) as cited in Vishwanath \& Palakonda (2011).

${ }^{3}$ In this article, the term "racialized" refers to "all people that are non-Caucasian in race or non-white in colour" as defined by the Canadian Observatory on Homelessness (n.d.).
} 
International Journal of Child, Youth and Family Studies (2021) 12(1): 124-142

White "saviour" complex; Lodhia, 2016) that further undermine women's rights and dignity, and reinforce existing power differences between mainstream White and racialized communities.

When Bill S-7 was passed in June 2015, its unfortunate title and its narrow focus drew considerable critical public attention and alarmed anti-racist, feminist, and community activists across Canada. They felt that, rather than highlighting the issue of gender-based and familial violence and the need to prevent violence against women and girls, the bill implicitly encouraged divisiveness, stigmatization and denigration of racialized communities and cultures, and the continued masking of the realities of cultural communities. The emphasis on the bill's divisiveness, the cultural ignorance of the Conservative-led government that tabled the bill, and the stigmatization of racial communities was clear in House of Commons debates on March 23, 2015 (Aubin, 2015) and elsewhere in public discourse during that period.

In the following work, we outline the changes made to legislation as a result of Bill S-7, and the justification for these changes. We critically explore the problematic elements of the bill such as the title, the redundancy of legislative amendments, and the pairing of "barbaric practices" with culture. We offer insight into how the Zero Tolerance for Barbaric Cultural Practices Act and amendments to related legislation failed to protect women and girls, and instead harmed and increased the risk of harm for those it claimed to support. We then identify the barriers to supporting survivors and provide some practical suggestions for effectively addressing family- and gender-based violence in Canada as needed steps in managing and preventing these multidimensional and complex issues on Canadian territory.

\section{Amendments to Legislation}

In its final approved version, Bill S-7 amended existing legislation to create new legal measures and create new criminal offences. Several amendments were made to the Immigration and Refugee Protection Act (IRPA), the Civil Marriage Act, the Criminal Code of Canada, the Prisons and Reformatories Act, and the Youth Criminal Justice Act. Overall, these changes were presented as having the objective of strengthening existing initiatives meant to provide support, protection, and services for immigrant women and girls specifically and, generally, for all newcomers to Canada (Government of Canada, 2014a). Some of these initiatives included the creation of a working group, educational pamphlets, and a voluntary Royal Canadian Mounted Police (RCMP) online training module (Government of Canada, 2014b). Other changes included:

- Polygamy was added to the inadmissibility criteria under IRPA to enable the exclusion of permanent residents and temporary residents if they practise polygamy;

- Amendments to the Prisons and Reformatories Act and the Youth Criminal Justice Act to support the use of a peace bond in cases of suspected FM or early marriage; 
- A national legal requirement of "free and enlightened consent" was included in the Civil Marriage Act as well as a new national minimum age for marriage of 16 years ${ }^{4}$;

- To prevent early marriages and FMs several measures were introduced:

$\circ$ A new specific court-ordered peace bond to be used when there is suspicion that one of these offences would be committed;

o Confiscation of passports to prevent a child from being taken out of the country to facilitate an FM;

- Amendments to legislation also made it a crime to:

o Officiate or solemnize a marriage knowing that it is in contravention of federal law;

- Celebrate, aid, or participate in a marriage rite or ceremony knowing that one of the persons being married is doing so against their will or is under the age of 16 years;

o Attempt to remove a child from Canada with the intention of undertaking an act that would be considered an offence if committed in Canada.

Changes were also made to the Criminal Code which limited the defence of provocation ${ }^{5}$ so that it would no longer apply in so-called "honour" killings and many spousal homicides. Narrowing the provocation defence limited its use to cases in which the conduct of the victim could be shown to constitute an indictable offence under the Criminal Code carrying a punishment of five years or more in prison ${ }^{6}$. Problematically, the Conservative government chose to retain the underlying premise of provocation whereby a rage-induced sudden loss of self-control could result in murder, while only changing what types of behaviour would be considered valid triggers of this loss-of-control response ${ }^{7}$.

\footnotetext{
${ }^{4}$ Interestingly, Canada is not a signatory to the United Nations Convention on Consent to Marriage, Minimum Age for Marriage and Registration of Marriages, 1962 whereby state parties were required to take legislative action to set a minimum age of marriage. In most of the signatory nations the minimum age of marriage is 18 or more.

${ }^{5}$ Provocation is a partial defence that only applies in charges of first or second degree murder. It is "partial" in that it reduces a murder conviction to manslaughter, but does not completely eliminate criminal culpability. It applies only to killings that result from a sudden loss of self-control arising from the criminal behaviour of the deceased. See Fitz-Gibbon (2014) for a detailed explanation of the provocation defence.

${ }^{6}$ This changed the long-standing definition of a provocation from "a wrong act or insult that is of such nature as to be sufficient to deprive an ordinary person of self-control" to "conduct of the victim that would constitute an indictable offense ... punishable by five or more years of prison" (Criminal Code, 1985, s 232[2]). The basic idea was that the victim had to have committed a serious crime against an accused for them to be able to argue that they were provoked into killing. See Proctor (2019) and Fitz-Gibbon (2014) for more information.

${ }^{7}$ An early use of the provocation defence was in cases involving homophobic and gender-based violence. For example, if a man killed his wife upon discovering her in the act of adultery, this was seen as a sudden, heat-ofpassion crime - less blameworthy than premeditated murder and undeserving of the death sentence (which was in effect when the defence was developed). No similar doctrine existed for a wife who found her husband in bed with another woman. Given that the death penalty was abolished in Canada and because of the discriminatory aspects of the original use of the provocation defence, some argue that the provocation defence should be removed from the
} 
International Journal of Child, Youth and Family Studies (2021) 12(1): 124-142

\section{Culturalizing Violence}

The paternalistic and colonial underpinnings of Bill S-7 were evident in a Government of Canada news release indicating that the aim of the bill was to warn immigrants coming to Canada to leave behind cultural practices that are "incompatible with Canadian values" (Government of Canada, 2014a). The amendments associated violence against women and girls with immigrants and minority cultures, which were deemed "barbaric" in comparison to the presumably "nonbarbaric" culture of mainstream Canadians. Such sentiments were echoed in statements by Ministers and officials such as that of Chris Alexander, the then Citizenship and Immigration Minister of Canada (Government of Canada, 2015):

Despite our best efforts and intentions, the reality is that some immigrant women can and do face violence or abuse. With the Zero Tolerance for Barbaric Cultural Practices Act, we are sending a strong message to those in Canada, and those who wish to come to Canada, that we will not accept the practice of cultural traditions that deprive individuals of their human rights. Our fair and generous immigration system will not extend to those who would carry out barbaric cultural practices on Canadian soil.

Alexander demonstrated a regressive understanding of culture; however, he was not alone in his beliefs. Similar sentiments about the illusion of cultural inferiority of immigrants versus the superiority of the dominant Eurocentric culture in Canada were reinforced by other members of cabinet, as exemplified by the words of Peter MacKay, the former Minister of Justice and Attorney General of Canada (Government of Canada, 2015):

Our Government is committed to ensuring that women and girls have the freedom to control their own destiny. In Canada, we value cultural diversity, but we are sending a strong signal that certain cultural practices that victimize vulnerable women and girls, including forced marriages and so-called "honour" killings, will not be tolerated in this country. I am pleased that our legislation is standing up for victims and gives us more tools to address these serious crimes, to provide women and girls a more secure future.

In this context, a woman's right to safety and protection from violence became associated with specific cultural groups and acquired racialized undertones, instead of being seen as rights for all women, with the violence being condemned in and of itself. This is an example of what scholars describe as the dividing line between the so-called "civilized" and the so-called "barbaric": the state is seen as the "saviour" of minority women who require "saving" from their own families, communities, and cultures (Abu-Lughod, 2002, 2006; Haque, 2010; Razack, 2007). Indeed, many aspects of Bill S-7 reflected the impulse to culturalize violence against racialized women by

Criminal Code of Canada altogether. See Grant and Parkes (2017) for a thorough history and assessment of the provocation defence. 
portraying racialized groups as the sole perpetrators of violence. When translated into legislation, such racist ideologies endanger minority and immigrant families and their communities and impede access to the supports and services that are vital for violence prevention (Haque, 2010). In Bill S-7, the complexity of violence against women - which is entangled in a web of social, economic, cultural, patriarchal, and political factors (Crenshaw, 1991; Gonçalves \& Matos, 2020; Sokoloff, 2008) — was reduced to the perceived cultural backwardness and barbarism of immigrants and minority communities in Canada.

\section{Problematic Elements of Bill S-7}

\section{Issues with the Short Title}

Introduced amidst an intensifying climate of perceived attacks on racialized women and their families, Bill S-7 was received with widespread trepidation among community workers, service providers, and social justice advocates. Many practitioners, allies, and survivors organized to draw mass attention to the systemic racism and colonial ideologies that were encapsulated in the title "Zero Tolerance for Barbaric Cultural Practices Act". First, the term "barbaric" created a clear division between the so-called "backward" and opposing "modern" cultures. The backwardmodern binary is reminiscent of the treatment of Indigenous communities throughout Canadian history: similar racist narratives were used against Indigenous communities to perpetuate similar racist legislation, narratives, and negative stereotypes surrounding Indigenous traditions, cultures, and practices; the effects continue to be seen in current Canadian policy and legislation (Switlo, 2002). These and other binaries (e.g., insider-outsider, minority-majority) target specific racialized and marginalized communities, are pervasive within Canadian society and history, and further perpetuate racist homogenized myths.

The title was strongly condemned by Senator Mobina Jaffer who introduced a private member's bill (Bill S-210) to change the title soon after Bill S-7 was passed (Smith, 2017). ${ }^{8}$ Central to her argument was the inappropriate pairing of the terms "barbaric" and "cultural", which, instead of condemning the wrongful nature of the actions considered "barbaric" regardless of any connection to specific cultures, ultimately removed agency from the perpetrators of these actions (Smith, 2017). The implication was that these practices are integral to certain cultures and these cultures are ultimately "barbaric". Indeed, it was challenging to look past the title because it was, in itself, deeply harmful for communities to be labelled "barbaric". Green Party leader Elizabeth May criticized the legislation, noting that it had a "bumper-sticker title" (para. 5), calling it "appalling" (para. 6), and seeing it as a tactic to "fan the flames" (para. 5) of regressive cultural beliefs in some groups (Payton, 2015a).

\footnotetext{
${ }^{8}$ See details in: Canada. Parliament. House of Commons. Debates, 41st Parliament, 2nd Session, vol.149, Issue 99, November 26, 2014.
} 
International Journal of Child, Youth and Family Studies (2021) 12(1): 124-142

Something worth noting is that the choice of title was made by the Conservative-led government in a climate where other xenophobic legislation and policies were being put forward, and there was an overall rise in racial intolerance in Canada, especially towards racialized women. Some examples include the intense debate surrounding whether or not Muslim women could wear the niqā $b^{9}$ during Canadian citizenship ceremonies (Macdonald, 2015; Payton, 2015b). Critics of that administration noted that it was engaging in a dangerous, xenophobic game by "grandstanding on an issue that involves a tiny minority of devout Muslim women in the country" (Coyne, 2015; Maloney, 2015). Further, the same administration announced an initiative to set up an RCMP telephone "tip line" where Canadians could report any "barbaric cultural practices", ignoring the existing phone lines for reporting criminal behaviour in Canada: 911 for emergencies and local police lines for non-emergencies (Andrew-Gee, 2015). This initiative received heavy criticism charging that it was divisive, xenophobic, and fear-mongering.

\section{Existing Measures in Legislation}

Bill S-7 presented complex challenges in its text, not just in its title. Much of the dissent it provoked came from social workers and law practitioners with years of experience working with survivors of early marriages or FMs, so-called "honour"-based violence, and other forms of familial and gender-based violence. In discussions of Bill S-7, whether in the general public or among former Conservative administration members who supported the bill, there was a widespread failure to acknowledge that many of the changes were unnecessary or redundant given existing legislation. For example, at the time the bill was introduced, polygamy was already a criminal offense in Canada (Criminal Code, 1985, Sec. 293) and the power to arrest and charge polygamists was well established, albeit underused (e.g., Bountiful), ${ }^{10}$. Bill S-7, however, made explicit that the focus was on the polygamy practices of immigrants, and immigrants alone. Further, the rationale for additional legislation surrounding polygamy was unclear given that the practice did not, and still does not, appear to be a widespread problem in Canada.

Additionally, the violence addressed in the bill involved a multitude of breaches of human rights laws and forms of discrimination against girls and women, all of which were already illegal under the Canadian Human Rights Act. For example, FM and early marriage are recognized internationally as violations of human rights as they involve the breach of the right to choose when, if, and whom to marry. In Canada, early marriage is one that involves someone under the age of 16, as such individuals cannot legally consent to marriage. FM is also considered human trafficking, a contemporary form of slavery punishable under Canadian legislation. The contexts within which these crimes arise may involve breaches of a person's right to bodily autonomy and freedom from violence, and these too were already punishable in Canada.

\footnotetext{
${ }^{9} \mathrm{~A}$ niqāb is a veil usually covering the face and body and is a highly visible manifestation of being a Muslim woman in the West. See Zempi (2016) for more information.

${ }^{10}$ Bountiful is a fundamentalist breakaway commune in southeastern British Columbia led by Winston Blackmore, who had an alleged 25 marriages that took place between 1975 and 2001. See more in Omand (2015).
} 
International Journal of Child, Youth and Family Studies (2021) 12(1): 124-142

Another issue concerning existing legislation surrounded the definition of FM, which failed to consider the full context in which FM arises. FM often involves emotional abuse and manipulation, physical or sexual violence, unlawful confinement, and abduction. Since the free and full consent of one of the parties is lacking, this type of marriage was already illegal and punishable by the Criminal Code (1985) in Canada at the time Bill S-7 was tabled. Member of Parliament Lysane Blanchette-Lamothe (2015) repeated the words of Canadian criminologist Madeline Lamboley, who had studied the criminalization of FM in her doctoral research:

"Canada is not without means to face this issue already, to the extent that it is possible to intervene legally under the criminal system to sanction reprehensible actions that arise in a large number of situations in forced marriages (threats, aggression, sexual assault, kidnapping, confinement, false marriages, extortion, intimidation, battery, murder, attempted murder, and so on).”

It is evident from parliamentary debates that expert advice from Dr. Lamboley and other professionals in the field was not incorporated into further amendments of the bill.

\section{Criminalization}

Despite the existence of applicable criminal laws, survivors of the type of violence addressed by Bill S-7 (e.g., FM) rarely disclose their experiences of violence to police and other enforcement agencies since their families are not only the perpetrators of the violence, but often the only social support of the survivors (Sabbe et al., 2014). This tension makes it difficult for survivors to approach law enforcement for help, as pursuing criminal action against their perpetrators would isolate them from their support system.

At the time that Bill S-7 was passed, Canada was not the only country to have implemented criminalization of FM, which had already been criminalized in Norway in 2003, Austria in 2006, Belgium in 2007, and Denmark in 2008 (Sabbe, 2014). Although many countries have now criminalized FM, the effectiveness of criminalization on preventing FM and protecting girls and women is unclear. Part of the issue is that FMs are often conducted privately or in secret, and may never be officially registered, making it challenging to identify and report FM (Global Justice Initiative, 2012). Another issue is that it is difficult to determine whether a person was forced into marriage, except in cases of non-consensual marriage induced by physical force. The overwhelming majority of FMs are the result of psychological coercion (Global Justice Initiative, 2012; Sabbe et al., 2014). Those against criminalization of FM argue that, overall, the consequences of criminalization for their families and communities deter those experiencing violence from coming forward (Clark \& Richards, 2008). In fact, a large majority of FM perpetrators are family members and survivors have expressed concern about getting family members "into trouble and wanting to protect their families regardless of their own victimization. ... [Survivors] indicate that they would be hesitant to seek outside assistance if this would result in criminal consequences for family members" (Anis et al., 2013, p. 28). Interestingly, there has not been a single reported case of anyone charged and prosecuted for FM in Canada. 
International Journal of Child, Youth and Family Studies (2021) 12(1): 124-142

Rather than encouraging victims to seek support, access services, reduce risk of further violence, and move towards a path of recovery from their FM, criminalization pushes them deeper underground (Clark \& Richards, 2008). Survivors and frontline service providers have made it clear that most people in the criminal legal system and many involved stakeholders are neither trained to manage the complexities of FM nor sensitive towards survivors' needs: these workers may lack, for example, trauma-informed training, adequate knowledge of available support services, and cultural knowledge and sensitivity (Sapoznik Evans, 2017). Unfortunately, in many cases where survivors disclose their story to authorities, they face discrimination and feel targeted and stigmatized by justice actors. Moreover, it has been observed that criminalization has the potential to lead to further targeting and overpolicing racialized communities (e.g., racial profiling, carding; see Giwa et al., 2020; Tanovich, 2006).

\section{Survivor Input}

Early in debates, it was clear that in the creation of Bill S-7 there was little, if any, input from survivors of gender-based and familial violence. Ironically, members of the government that tabled the bill claimed to have listened to "actual victims" when, in reality, the only known consultations completed were carried out in private with individuals unknown to the public who had been handpicked by the administration, and were not explicitly identified as "victims" or survivors (Blanchette-Lamothe, 2015; Menegakis, 2015).

As a result, many of the changes enacted under Bill S-7 did not consider survivor impact; in fact, some of the changes had the potential to increase the risk of violence to survivors. For example, if a woman experiencing violence applied for a Peace Bond, under Bill S-7 they would have to appear in court with the perpetrator. Alternatively, a third party could apply for a Peace Bond on the survivor's account; however, the perpetrator would still receive notice of the application. In either event, the survivor may be at increased risk of harm if she and the perpetrator reside together. If the applicant is underage, to expect them to manage this process and navigate the criminal legal system without the support of their family, who may very well be the perpetrators or involved in perpetuating violence, is highly unrealistic. Furthermore, in seeking support and safety, a survivor may risk the deportation of her own family — her support system — and other adverse consequences within their community.

Through consultation with survivors, the federal government could have made concrete changes to Bill S-7 that would have better supported others experiencing violence. For instance, they might have learned that, as with any other gender-based and family violence issue, the most important and effective measure to combat violence is to provide public education and to raise awareness among professionals, from teachers and service providers to lawyers, lawmakers, judges, immigration officials, foreign affairs officials, and law enforcement officers. 
International Journal of Child, Youth and Family Studies (2021) 12(1): 124-142

\section{Understanding Early and Forced Marriage}

Something that appeared lost in parliamentary debates of Bill S-7 was a detailed definition of FM and the distinctions between consensual and non-consensual marriage. The issue of early marriage and FM is subject to many misconceptions, the most common being that there is no difference between FMs and arranged marriages. In reality, arranged marriages, which are common in many communities, require a collective decision of families, a clear choice, and, crucially, the free consent of the parties getting married. On the other hand,

a forced marriage is a form of violence and an abuse of human rights. It is a practice in which a marriage takes place without the free consent of the individuals getting married. Forced marriage can happen to anyone; of any gender, of any age. (Chokshi et al., 2010, p. 3)

Such definitions of FM have evolved from extensive discussions and debates in the literature and the work of civil society organizations around the globe. Unfortunately, there was minimal discussion of the importance of definitional distinctions among those in support of Bill S-7; in fact, there appeared to be a misunderstanding of what constitutes FM. Madeline Lamboley, the expert who had conducted an in-depth examination of criminalization of FM in Canada explained that, as a society, we do not know the extent of the problem of FM and questioned the function of criminalization as a solution to a phenomenon that is so poorly understood here (BlanchetteLamothe, 2015).

The issue of FM, like many other issues related to family and gender-based violence, is complex. It is commonly perceived by the Canadian mainstream as a particular cultural practice, which amounts to a denial of accountability from the larger society. Not only is this an issue that must be addressed within Canadian culture, but it has become the subject of public and political debate on a global level (Bendriss, 2008; Sabbe et al., 2014). While FM is often regarded as a common practice among immigrants from South Asia, the Middle East, and certain parts of Africa, it occurs in many cultures and faiths while yet being condemned by most communities and religions (Bendriss, 2008). In fact, "every major faith condemns the practice and requires freely giving consent for marriage, as does the law in most states" (Dostrovsky et al., 2007, Ch. 1, sec. $1.1)$.

The reality remains that FM occurs across intersections of race, religion, geography, socioeconomic status, and class (Crenshaw, 1991; Gonçalves \& Matos, 2020). Survivors from a wide variety of backgrounds have been forced into matrimonial arrangements by their families under false pretences or through physical abuse, emotional abuse, and exploitation (Bendriss, 2008; Dostrovsky et al., 2007). However, it is common that individuals facing FM are marginalized on a number of intersecting levels relating to race, income, immigration status, and language, and face significant barriers to equality (Chokshi et al., 2010). This marginalization contributes to the conditions leading to FM and other familial violence. 
International Journal of Child, Youth and Family Studies (2021) 12(1): 124-142

The definition of FM in Bill S-7 is broad and vague, which makes it unpredictable and challenging to apply in practice. The changes to legislation in Bill S-7 did not consider the fact that crimes involving extortion, assault, or kidnapping could already be prosecuted as such under the Criminal Code, whether or not an FM was contemplated.

\section{Contradiction in the Act}

Protecting girls and women was the articulated goal of Bill S-7; however, the changes made in it go against the federal obligation to protect the rights of all women. It made significant changes to immigration law, prohibiting sponsorship for anyone who is, or intends to be, practising polygamy with another person who is also in Canada. This particular clause prevents many vulnerable women from entering Canada at all.

Further, if an individual did come forward and disclosed past or ongoing family violence, criminal sanctions or deportations could result in vulnerable children losing their parents or caregivers, and possibly their entire support systems. The prevalence of polygamy is extremely low in Canada. If a woman has been forced into a polygamous marriage abroad, are she and her children inadmissible to Canada? This and similar questions highlight the bill's contradictions with respect to its stated overall goal of protecting girls and women.

\section{Discussion}

\section{Barriers to Addressing Violence}

In work with survivors of gender-based and family violence, especially in cases of FM and "honour"-based violence, there are a number of policy restrictions and legal and social barriers to addressing these issues. These barriers and gaps include but are not limited to:

- Lack of protocols at an institutional level: There is a lack of training programs for relevant public officials including law enforcement, local administration officers, and those working in other fields involving the protection of girls and women. Training may include identifying early warning signs, risk assessment, safety and action planning, education about rights and responsibilities, resources and assistance to connect survivors with appropriate services, and offering non-judgemental and empathetic support. Lack of knowledge may lead to bias and misunderstanding, and compromise efforts to help.

- Jurisdictional issues: Across jurisdictions there are various and conflicting civil, religious, and customary laws relating to marriage. There are many factors that affect the ability to support survivors and punish perpetrators including plural legal systems that are inconsistent with international obligations, basing the minimum age of marriage on the age of criminal responsibility, the age of sexual consent, or the onset of pregnancy or puberty.

- Lack of trust between communities and authorities: There is reluctance on the part of victims to disclose information related to familial and gender-based violence; this may stem 
International Journal of Child, Youth and Family Studies (2021) 12(1): 124-142

both from concern over stigma and from the fear that the family will learn of the disclosure. Criminalization of early marriage or FM may deter victims, especially those from immigrant or minority communities, from coming forward, particularly if it may result in criminal prosecution and imprisonment of family members. This highlights the need to accompany legal reforms with awareness-raising efforts for families and communities.

- Cultural racism and stereotyping of the issue: When considering culture in relation to women's rights and gender-based violence, one must avoid the decontextualized evocation of stereotyped roles that pits an idealized Western culture, with its focus on the individual, against foreign practices that are conceived as alien. Such culture-based conceptualizations of gender-based violence obscure the complexities of women's lived experiences of violence, resulting in the exclusion from state protection of women who have experienced multiple forms of marginalization. In the context of violence against women, we have observed that this confusing use of the notion of "culture" bypasses supporting equitable protection from abuse and instead creates a hierarchical model in which some are in need of more protection than others. Moreover, cultural stereotyping of gender-based violence and women's experiences with violence across cultures creates barriers for diverse women when they attempt to access services. For example, survivors may avoid accessing services when they feel that to do so will support or contribute to stereotypical conceptions of their culture. When women do attempt to seek services, service providers may exhibit bias in screening mechanisms, risk assessment, and the type and level of assistance offered.

- Complexities related to the immigration and refugee process: As with the issues surrounding lack of trust between communities and authorities, disclosing familial violence may affect the citizenship, sponsorship, and independence of women who experience this violence. Citizenship and Immigration Canada must commit to updating policy exemptions for survivors of familial violence, including FMs, and provide exemptions from conditional permanent residence in FM situations.

Alongside these barriers, the societal context makes it difficult to address FM due to the compounding effect of the intersections of social and economic position, regressive immigration policies, xenophobia, racism, heterosexism, homophobia, and poverty.

\section{Combatting Violence}

While gender-based and family violence are multifaceted, complex issues to address, specialist services have made consistent recommendations that take into account input from front-line service providers and survivors in order to prevent violence against girls and women in racialized communities. First and foremost, there is a need to focus on prevention, and not the prohibition that was a central tenet of Bill S-7. Criminalization and stringent immigration policies will not protect girls and women from experiencing violence; instead, they make it more difficult for victims to come forward while offering little or no protection in return (Sabbe et al., 2014). While legislative efforts are undoubtedly important, it is critical to ensure that interventions are available 
International Journal of Child, Youth and Family Studies (2021) 12(1): 124-142

that directly support the health and wellness of vulnerable individuals who are at risk of, or are survivors of, gender-based and family violence.

Beyond legislation, education and awareness-building are well known to be the most effective preventive tools for such violence. Education in this context involves extensive, ongoing training for all invested stakeholders. A coordinated, multisectoral approach is essential to support the wellbeing, health, and safety of women. Service providers with a direct and indirect role in supporting victims, such as local authorities, police, the judiciary, teachers, community groups, mental health professionals, and social workers, would benefit from additional culturally appropriate education and training concerning the different types of gender-based and familial violence and how to respond appropriately. This includes trauma-informed services, risk assessment, and safety planning within a framework that is survivor-centric and takes account of the complex reality of violence, immigration status, racial identity, sexuality, gender identity, and other complexities that survivors must continue to negotiate while getting support. Considering the cultural ignorance evident in the debates surrounding Bill S-7, it is clear that political leaders would also benefit greatly from this education. Implementing these recommendations would demonstrate a commitment to bring about real change and provide appropriate support for survivors.

\section{Concluding Thoughts}

There are considerable challenges in managing the complex environment in which family and gender-based violence occurs; however, Bill S-7 fell very short of its goal of protecting women and girls. The title of the bill, in itself harmful and hurtful to racialized communities, was an early indication that the Act and the amendments it embodied would fail the very people it sought to support. The cultural aspect of the practices condemned in Bill S-7 further fanned the flames of the cultural divisiveness that was increasing in the years leading up to its introduction. Bill S-7 was quietly passed with no additional training, educational, or funding programs to further its purposes. Lack of such programs not only creates potential harmful contexts in which disclosures may be made and hinders early identification of violence but also makes it challenging to track the effectiveness of the law in attaining its proclaimed purpose of offering greater protection and support to vulnerable women and girls (Sheppard, 2000). Women must not be forced to choose between living with danger in their homes and putting their or their family members' immigration status in jeopardy (Sheppard, 2000).

Moving forward, there are many suggestions that could be made to address family and genderbased violence as well as to support survivors of such violence. Above all, we suggest that implementation of best practices such as educating and raising awareness within the immigration, law enforcement, health, and education sectors is essential to protect women and girls from violence. In addition, it is crucial to incorporate monitoring mechanisms into training and educational programs in order to understand how to develop and adapt programming to better suit the needs of survivors. 
International Journal of Child, Youth and Family Studies (2021) 12(1): 124-142

Overall, Bill S-7 was a futile effort to protect girls and women of racialized groups in Canada. It failed to support survivors who have experienced or are experiencing violence, and it failed to acknowledge and address the complexity of the intersectionality of familial and gender-based violence. In this article, we stand for survivors of familial and gender-based violence, whose voices have told us time and time again that they will not come forward if it means criminal sanctions or deportation for their own family. We must continue to ensure that survivors and not perpetrators are at the centre of these discussions. 
International Journal of Child, Youth and Family Studies (2021) 12(1): 124-142

\section{References}

Abu-Lughod, L. (2002). Do Muslim women really need saving? Anthropological reflections on cultural relativism and its others. American Anthropologist, 104(3), 783-790. doi:10.1525/aa.2002.104.3.783

Abu-Lughod, L. (2006, September 1). "The Muslim woman: The power of images and the danger of pity." Eurozine. https://www.eurozine.com/the-muslim-woman/

Andrew-Gee, E. (2015, October 2). Conservatives vow to establish 'barbaric cultural practices' tip line. The Globe and Mail. https://www.theglobeandmail.com/news/politics/conservativesvow-to-establish-barbaric-cultural-practices-tip-line/article26640072/

Anis, M., Konanur, S., \& Mattoo, D. (2013). Who / if / when to marry: The incidence of forced marriage in Ontario. South Asian Legal Clinic of Ontario. http://www.sawc.org/wpcontent/uploads/2013/01/SALCO-Who-If-When-to-Marry-The-Incidence-of-ForcedMarriage-in-Ontario-Sep-2013.pdf

Aubin, R. (2015, March 23). "Zero Tolerance for Barbaric Cultural Practices Act". House of Commons Debates: Official report (Hansard), 147(187).41st Parliament, 2nd Session, pp. 12144-12155. https://www.ourcommons.ca/Content/House/412/Debates/187/HAN187E.PDF

Bendriss, N. (2008). Report on the practice of forced marriage in Canada: Interviews with frontline workers. Exploratory research conducted in Montreal and Toronto in 2008. Department of Justice Canada. https://www.justice.gc.ca/eng/rp-pr/cj-jp/fv-vf/fm$\underline{\mathrm{mf} / \mathrm{index} \cdot \mathrm{html}}$

Bill S-7: An Act to amend the Immigration and Refugee Protection Act, the Civil Marriage Act and the Criminal Code and to make consequential amendments to other Acts. (2014). 41st Parliament, 2nd Session.

https:/www.parl.ca/LegisInfo/BillDetails.aspx?Bill=S7\&Language=E\&Mode=1\&Parl=41\&S $\underline{\mathrm{es}=2}$

Blanchette-Lamothe, L. (2015, June 16). "Zero Tolerance for Barbaric Cultural Practices Act". Canada. Parliament. House of Commons. Edited Hansard, 148(232), 41st Parliament, 2nd Session. https://www.ourcommons.ca/DocumentViewer/en/41-2/house/sitting-232/hansard

Canada. Parliament. House of Commons. Debates, 42nd Parliament, 1st Session, Vol. 149, Issue 99, June 18, 2018 (Online). Retrieved from https://openparliament.ca/bills/42-1/S-210/

Canadian Observatory on Homelessness. (n.d.). Racialized communities. Homeless Hub. https://www.homelesshub.ca/solutions/priority-populations/racializedcommunities\#: : :text $=$ Frequently 
International Journal of Child, Youth and Family Studies (2021) 12(1): 124-142

Chokshi, R., Khanna, A. \& Silim, A. (2010). Forced/non-consensual marriages: A toolkit for service providers. South Asian Legal Clinic of Ontario. https://salc.on.ca/Documents/FM/Forced Marriage - Toolkit2016.pdf

Clark, B., \& Richards, C. (2008). The prevention and prohibition of forced marriages:A comparative approach. The International \& Comparative Law Quarterly, 57(3), 501-528. doi:10.1017/S0020589308000390

Coyne, A. (2015, October 1). Andrew Coyne: To uncover or not to uncover: Why the niqab issue is ridiculous. National Post. https://nationalpost.com/opinion/andrew-coyne-to-uncover-or$\underline{\text { not-to-uncover-why-the-niqab-issue-is-ridiculous }}$

Crenshaw, K. (1991). Mapping the margins: Intersectionality, identity politics, and violence against women of color. Stanford Law Review, 43(6), 1241-1299. doi:10.2307/1229039

Criminal Code, RSC 1985, c. C - 46. (Online). https://laws-lois.justice.gc.ca/eng/acts/C46/section-293.html

Crockatt, J. (2015, March 23). "Zero Tolerance for Barbaric Cultural Practices Act”. Canada. Parliament. House of Commons. Hansard, 147(187), 41st Parliament, 2nd Session. https://www.ourcommons.ca/Content/House/412/Debates/187/HAN187-E.PDF

Dostrovsky, N., Cook, R. J., \& Gagnon, M. (2007) Annotated bibliography on comparative and international law relating to forced marriage.. Department of Justice Canada. https://www.justice.gc.ca/eng/rp-pr/fl-lf/famil/mar/co.html

Fitz-Gibbon, K. (2014). Homicide law reform, gender and the provocation defence: A comparative perspective. Palgrave Macmillan. doi:10.1057/9781137357557

Giwa, S., Mullings, D. V., Adjei, P. B., \& Karki, K. K. (2020). Racial erasure: The silence of social work on police racial profiling in Canada. Journal of Human Rights and Social Work, 5(4), 224-235. doi:10.1007/s41134-020-00136-y

Global Justice Initiative. (2012, October 4). Denmark's forced marriage law under fire [Blog post]. http://globaljusticeinitiative.wordpress.com/2012/10/04/denmarks-forced-marriage-lawunder-fire/

Gonçalves, M., \& Matos, M. (2020). Interpersonal violence in immigrant women in Portugal: An intersectional approach. Journal of Immigrant \& Refugee Studies, 18(1), 22-41. doi:10.1080/15562948.2018.1557312

Government of Canada. (2014a). Protecting Canadians from barbaric cultural practices [News release]. https://www.canada.ca/en/news/archive/2014/11/protecting-canadians-barbariccultural-practices.html 
International Journal of Child, Youth and Family Studies (2021) 12(1): 124-142

Government of Canada. (2014b). Key federal initiatives protecting and supporting vulnerable women and girls [News release]. https://www.canada.ca/en/news/archive/2014/11/keyfederal-initiatives-protecting-supporting-vulnerable-women-girls.html

Government of Canada. (2015). Zero Tolerance for Barbaric Cultural Practices Act receives royal assent. [News release]. https:/www.canada.ca/en/news/archive/2015/06/zero-tolerancebarbaric-cultural-practices-act-receives-royal-assent.html

Grant, I., \& Parkes, D. (2017). Equality and the defence of provocation: Irreconcilable differences. Dalhousie Law Journal, 40(2), 455-495.

Haque, E. (2010). Homegrown, Muslim and other: Tolerance, secularism and the limits of multiculturalism. Social Identities: Journal for the Study of Race, Nation and Culture, 16(1): 79-101. doi:10.1080/13504630903465902

Johnson, H., \& Kapoor, P. (2013). The case for a national action plan on violence against women [Report]. Canadian Network of Women's Shelters and Transition Houses.

Lodhia, S. (2016). Beyond rescue: Rethinking advocacy and intervention in the women's and gender studies classroom. Feminist Teacher, 27(1), 1-23.

Macdonald, N. (2015, September 28). The niqab debate, let's not forget, is about individual rights. Canadian Broadcasting Corporation. https://www.cbc.ca/news/politics/canadaelection-2015-niqab-neil-macdonald-1.3246179

Maloney, R. (2015, October 2). Tories pledge tip line to contact 'barbaric cultural practices'. https://www.huffingtonpost.ca/2015/10/02/tip-line-barbaric-cultural-practicestories n 8234610.html?utm hp ref=canada-politics

Mattoo, D., \& Sekhar, K. (2012). Forced (non-consensual) marriage: A South Asian Canadian context. In M. Gupte, R. Awasthi, \& S. Chickerur (Eds.), 'Honour' and women's rights: South Asian perspectives (pp. 413-444). MASUM Publications \& International Development Research Centre.

Menegakis, C. (2015, June 16). "Zero Tolerance for Barbaric Cultural Practices Act”. Canada. Parliament. House of Commons. Edited Hansard, 148(232). 41st Parliament, 2nd Session. https://www.ourcommons.ca/DocumentViewer/en/41-2/house/sitting-232/hansard

Mucina, M. K. (2018). Exploring the role of "honour" in son preference and daughter deficit within the Punjabi diaspora in Canada. Revue Canadienne d'Études Du Développement, 39(3), 426-442. doi:10.1080/02255189.2018.1450736

Olwan, D. M. (2013). Gendered violence, cultural otherness, and honour crimes in Canadian national logics. Canadian Journal of Sociology, 38(4), 533-556. doi:10.29173/cjs21196 
International Journal of Child, Youth and Family Studies (2021) 12(1): 124-142

Omand, G. (2015, June 8). Bountiful leader Winston Blackmore didn't get 'fair notice' polygamy is illegal, argues lawyer. Canadian Broadcasting Corporation. https://www.cbc.ca/news/canada/british-columbia/bountiful-leader-winston-blackmore-didnt-get-fair-notice-polygamy-is-illegal-argues-lawyer-1.3104352

Payton, L. (2015a, March 13). 'Barbaric cultural practices' bill all about politics, Elizabeth May says. Canadian Broadcasting Corporation. https:/www.cbc.ca/news/politics/barbariccultural-practices-bill-all-about-politics-elizabeth-may-says-1.2994274

Payton, L. (2015b, October 6). Election issues 2015: A Maclean's primer on the niqab. Canadian Broadcasting Corporation. https://www.macleans.ca/politics/ottawa/election-issues-2015-amacleans-primer-on-the-niqab/

Proctor, J. (2019, April 17). Law changed to protect vulnerable women had opposite effect, B.C. judge finds. Canadian Broadcasting Corporation. https://www.cbc.ca/news/canada/british$\underline{\text { columbia/provocation-defence-domestic-violence-1.5100281 }}$

Razack, S. H. (2007). The 'Sharia law debate' in Ontario: The modernity/premodernity distinction in legal efforts to protect women from culture. Feminist Legal Studies, 15(1), 332. doi:10.1007/s10691-006-9050-X

Sabbe, A., Temmerman, M., Brems, E., \& Leye, E. (2014). Forced marriage: An analysis of legislation and political measures in Europe. Crime, Law, and Social Change, 62(2), 171-189. doi:10.1007/s10611-014-9534-6

Sapoznik Evans, K. A. (2017). Forced marriage in Canada: To criminalize or not to criminalize. Canadian Journal of Human Rights, 6(1), 49-86. https://cjhr.ca/articles/vol-6-no-12017/forced-marriage-in-canada-to-criminalize-or-not-to-criminalize/

Shalabi, D., Mitchell, S., \& Andersson, N. (2015). Review of gender violence among Arab immigrants in Canada: Key issues for prevention efforts. Journal of Family Violence, 30(7), 817-825. doi:10.1007/s10896-015-9718-6

Shalhoub-Kevorkian, N. (2002). Femicide and the Palestinian criminal justice system: Seeds of change in the context of state building? Law \& Society Review, 36(3), 577-606. $\underline{\text { doi: } 10.2307 / 1512163}$

Sharify-Funk, M. (2013). Pervasive anxiety about Islam: A critical reading of contemporary 'clash' literature. Religions, 4(4), 443-468. doi:10.3390/rel4040443

Sheppard, C. (2000). Women as wives: Immigration law and domestic violence. Queen's University Law Journal, 26, 28. 
International Journal of Child, Youth and Family Studies (2021) 12(1): 124-142

Smith, M-D. (2017, December 12). Senate passes bill to remove mention of 'barbaric cultural practices' from Harper-era law. The National Post. https://nationalpost.com/news/politics/senate-passes-bill-to-remove-mention-of-barbariccultural-practices-from-law-passed-by-harper-conservatives

Sokoloff, N. J. (2008). Expanding the intersectional paradigm to better understand domestic violence in immigrant communities. Critical Criminology, 16(4), 229-255. doi:10.1007/s10612-008-9059-3

Switlo. (2002). Modern day colonialism - Canada's continuing attempts to conquer Aboriginal peoples. International Journal on Minority and Group Rights, 9(2), 103-141. doi:10.1163/157181102761163082

Tanovich, D. M. (2006). The colour of justice: Policing race in Canada. Irwin Law.

Vishwanath, J., \& Palakonda, C. S. (2011). Patriarchal ideology of honour and honour crimes in India. International Journal of Criminal Justice Sciences, 6(1-2), 386-395

Zaman, M., \& Koski, A. (2020). Child marriage in Canada: A systematic review. PloS One, 15(3), e0229676-e0229676. doi:10.1371/journal.pone.0229676

Zempi, I. (2016). 'It's a part of me, I feel naked without it': Choice, agency and identity for Muslim women who wear the niqab. Ethnic and Racial Studies, 39(10), 1738-1754. doi:10.1080/01419870.2016.1159710

Zero Tolerance for Barbaric Cultural Practices Act, SC 2015. c. 29. https://parl.ca/DocumentViewer/en/41-2/bill/S-7/royal-assent 